\title{
The Observed Experiences of Music Therapy on Parent-child Interaction for Families with Children with Down Syndrome
}

\author{
Jess O' Donoghue ${ }^{1 *}$ \\ 1 University of Limerick \\ *odonoghuejessica@gmail.com \\ Received: 24 September 2016 ; Accepted: 17 May 2017 ; Published: 1 July 2017 \\ Editor: Daphne Rickson Reviewers: Dorothea Pienaar, Jane Edwards
}

\begin{abstract}
The relationship between the quality of parent-child interactions and positive child development is well established in the literature. Nevertheless, parental and familial factors may pose risks to parents' capacity to participate in quality interactions with their children. Families with a child with a disability in particular are more likely to experience social isolation, and higher levels of parenting stress. Early intervention programmes to promote positive parent-child interaction for these families is well recognised. However, there is a lack of literature about the effectiveness of such programmes for these families. This research study explores music therapy on parent-child interaction, specifically focusing on children with a diagnosis of Down syndrome (DS). This case study involves two in-depth cases of children diagnosed with DS and their primary caregivers. The study documents individual music therapy sessions which took place over a six week period. The case study materials were gathered through the researcher's direct observations, fieldwork notes, and reflective journal logs. The music therapy block encouraged the primary caregivers to be more responsive during parent-child interactions. Furthermore, the children involved learned to engage and share musical activities with their mothers.
\end{abstract}

Keywords: Down syndrome, music therapy, parent-child interaction, music and parent-child attachment

\section{Introduction}

Down syndrome (DS), commonly referred to as trisomy 21, is the most common form of intellectual disability. In $97 \%$ of cases, DS is caused by a third chromosome 21 in all cells. The remaining 3\% of individuals with DS have either a form called 'translocation,' in which the extra chromosome becomes attached onto another chromosome, or a form called 'mosaic,' in which not all cells are affected (Down Syndrome Ireland, 2013). DS is the most common birth disorder, and prevalence varies between 1:500 and 1:1000 (Frid, Drott, Lundell, Rasmussen, \& Annerén, 1999). The prevalence of DS in Ireland is 1 out of every 546 live births, which is the highest in Europe (Down's syndrome Medical Interest Group, 2001). Due to an increase in antenatal detection, the incidence of DS is generally falling in other European countries. Ireland, however, continues to have one of the highest prevalence rates due to policy of termination 
of pregnancy (Hoey \& Murphy, 2006). Common features associated with DS include specific physical abnormalities, heart defects, visual and hearing impairments, and immune system deficiencies. Furthermore, these children develop at a slower rate when compared to their typically developing peers (Selikowitz, 1990). This is of particular significance for the areas of interaction and attachment (Goldberg, 2000).

\section{Personal Stance of the Researcher}

For the requirements of the Master of Arts in Music Therapy degree, the researcher was placed at a Creative Learning Centre as a music therapy student, providing individual and group music therapy to children with DS and their parents/primary caregivers. This fieldwork placement is one of the motivating factors behind the current research. The music therapy sessions delivered were based on the early parenting intervention programme Sing \& Grow (Abad \& Williams, 2007). This programme aims to support positive parent-child relationships and to build effective parenting skills through structured, music-based activities. The researcher used songs, musical games, and instrumental play to strengthen parent-child relationships and to promote children's developmental skills. Over the course of this placement, the researcher noticed progress and changes in both group and individual sessions. Additionally, the researcher's undergraduate background was also considered when investigating this area. The researcher graduated from the National University of Ireland, Galway with a B.Sc. (Hons.) Speech and Language Therapy degree. She has always been passionate about the area of communication and interaction, thus leading her to merge this element into the current research.

\section{What is Parent-child Interaction, and Why Is It Important?}

Among the most powerful formative influences on a child's development are those early interactions between a child and his/her primary caregiver. Much evidence supports this assumption, but it is still far from having a comprehensive and clear framework of knowledge about exactly how and why parent-child interactions exert their influence on the developing child. Parent-child interaction is a bi-directional process in which the behaviours of each partner influence and shape future responses, expectations, and conceptions of the other participant, and a child's development is a result of this process (Cicchetti \& Beeghly, 1990). Studies of parent-child interaction where the child may be considered at risk from a developmental delay are becoming increasingly more prominent.

\section{DS: Attachment and Interaction Issues}

Bowlby (1982) described attachment as the relationship between a child and caregiver involved with making the child safe and protected. The purpose of attachment is not to entertain or play with the child; it is where the child uses his/her primary caregiver as a secure base from which to explore and as a source of comfort (Waters \& Cummings, 2000). Attachment and interaction behaviour of infants with DS has received more attention than any other group of developmental disabilities (Cicchetti \& Beeghly, 1990). Some of these studies are comparative in nature, and researchers have used Ainsworth's (1978) 'strange situation' procedure in their investigations. Based on the child's responses to the interactive behaviour and the separation in the reunion episodes, scores are assigned for proximity seeking, resistance, avoidance, and contact maintenance. Vaughn, Goldberg, Atkinson, Marcovitch, MacGregor, and Seifer (1994) assessed three samples of children with DS using the strange situation test. They found that children with DS display insecure attachment style relative to typically developing children who generally display a secure attachment to their primary caregiver, as they are less reactive to their primary caregiver. Furthermore, Serafica and Cicchetti (1976) found that when comparing DS and typically developing children of approximately 2 years of age, only one child out of 12with DS cried during the observation period. The 
frequency of other vocalisations by the children with DS was also much lower, and they sought contact with their mothers less often.

\section{Music Therapy for Children with DS}

Specific information about children with DS and music therapy is limited. Of the studies of music therapy for children with DS, Pienaar (2012) explored the perceptions of music therapy among caregivers of children with DS. Pienaar developed a 29-item questionnaire based on other checklists for children with developmental disabilities and for music therapy. Caregivers strongly believed that children with DS enjoy music, like to move/dance when they hear music, and like to perform. The caregivers also indicated that conversation without words is possible in a music therapy session. There was a general agreement that children with DS recognised songs, laughed a lot, made sounds during music therapy sessions, and liked to sing. According to the caregivers, the children were keen to play instruments, imitate movements and sounds and have a fair sense of rhythm. The motivational aspect of music was also acknowledged. This suggests a potentially important aspect of music therapy for this population as literature indicates that children with DS can have poor motivation (Turner \& Alborz, 2003).

Daudt (2002) explored the experience of music in children with DS by use of a descriptive parental survey. The survey was used to determine how parents of children with DS describe their child's affective, social, and behavioural responses to a musical environment. The main goals of this study were to explore the experience in music of children with DS by descriptive parental report and to assess the attitudes and beliefs that parents of children with DS have about their child and music. Responses to items pertaining to 'quality of life' demonstrate that according to their parents, children seemed to enjoy music and want to be involved with it in a variety of ways. One-hundred percent of respondents agreed with the statement "my child likes music." Respondents agreed that their child seems happy when listening to, playing, or singing music. The last items on the survey pertained to music as a means of socialization. Parents' responses reveal that their children are likely to engage in musical activities with others. The results of this study appeared to say that parents believed that music enhances their child's quality of life, that it helps with personal organisation, and that it fosters social interaction.

Cunningham's (2011) chapter 'Music therapy to promote attachment between mother and baby in marginalised communities' described her work with a group of mothers and their babies with DS. She found that the behaviours that were demonstrated between the participants in the group appeared to reflect the difficulties in the early relationship, "the gleam was absent from the mother's eye and so the baby, not being sufficiently fed by her gaze, was powerless to enter the relating space" (p.117). She reported that music acted as a catalyst in the shift of the baby and the mother towards each other. Musical sounds were adapted and changed in these music therapy sessions to achieve harmony, as it is the moving and shifting of baby and mother to find a similar harmony or attunement in their relationship which helps the baby to learn about him/herself. Singing with a soft and breathy tone on a classical guitar, Cunningham delivered music into the mother and baby pairs which promoted effective relating. While this literature documents parent-child programs in music therapy, the impact of music therapy on parent-child attachment and interaction where DS is concerned is generally under reported and researched.

\section{Music Therapy and Parent-child Attachment}

Music plays a significant role in the early interaction and attachment between an infant and his/her primary caregiver. Trevarthen (2004) reported that infants are highly responsive to music. Young children have the capacity to imitate vocalisation, beat, pitch, and rhythm. At a young age, they learn to recognise typical nursery rhymes and join in with clapping, vocalizing, and other movements within song. When communicating with their children, parents use what is called 'motherese.' Motherese, also re- 
ferred to as infant-directed speech, is the spontaneous way in which primary caregivers speak with young children (Saxton, 2008) and comprises the following characteristics: higher pitch, exaggerated pitch excursions, and large dynamic range (Trehub, 2009). In addition to motherese, parents make use of infant-directed singing which has similar features to motherese. Infant-directed singing has been found to communicate emotional information and to coordinate mother-infant emotional state (de l'Etoile, 2006). Motherese and infant-directed singing are at the core of intimate interactions and pursue goals such as soothing and calming, engagement, and emotion-sharing (Trehub, 2009).

In early communication between child and primary caregiver, music is intuitively used for interaction, emotional regulation, and affect-attunement. Findings from the field of developmental psychology suggested that the medium of music is a valuable tool in working with young children and their parents. Daniel Stern (1985) is considered one of the key theorists in the area of parent-child relationships and uses musical terms to describe favourable parent-child communication such as resonance, rhythmic joining, and the 'dance' of parent-child relationships. Furthermore, Edwards (2011) reported that a primary caregiver and his/her infant experience early relating through music. Due to the nature and musical underpinnings of parent-child interaction, music seems to reach the parent and child at the very heart of their interactions.

In music therapy, parent-child work has gradually developed as a professional interest with recognised leaders including Abad and Williams (2007).In the context of parent-child work, music therapy is described as a process of developing a relationship with a parent/caregiverto develop, support, and extend his/her skills in using musical and music-like interactions including lullabies, songs, and rhymes to enhance and promote sensitivity, the mother's ability to respond to the child's signals appropriately, (Ainsworth, Bell, \& Stayton, 1974), mutual regulation (Edwards, 2011), and the emotional reciprocity between child and parent/caregiver as mutual regulation (Eriskson, 1950).

Parent-child attachmentcan be developed using musical means (Abad \& Edwards, 2004). Because music supports play and the communicative functions of play, it acts as a powerful medium for bringing primary caregivers/parents and their children together. The nonverbal aspects of music facilitate mutuality between parent and child and provide expression, playfulness, and freedom (Loveszy, 2006). The benefits when family members are included in music therapy with children have been reported in a wide range of contexts including paediatric burns, oncology, and neonatal intensive care units (Edwards, 2011). Allgood (2005) found that working with family members through music-based activities is effective for parent-child attachment and interaction.

Where developmental disabilities are concerned, Gilboa and Roginsky (2010) carried out a study which investigated the use of music therapy in developing the relationship and communication patterns between a mother and her child with cerebral palsy. The programme was music based with music being used more than $80 \%$ of the time during therapy sessions. Gilboa and Roginsky noted that some of the most significant turning points in the 8-week block occurred in the music. Results showed that communication increased during this therapy block in both verbal and non-verbal channels. The positive experiences that the mother and child had during the therapy encouraged them to speak to each other more freely. Relationships also improved during this work. Initially, the mother found it very difficult to let go of her child and to give him the space he needed. However, as the therapy progressed, the mother was able to let go of her child, and he responded accordingly.

Music therapy is effective with children with developmental disabilities, and music therapy has been found to be efficacious in facilitating parent-child relationships. The limited research with relation to DS offered an opportunity for the researcher to look at parent-child interaction in a context such as her music therapy placement. The key question behind this research study was, in what ways can music therapy promote parent-child interactions between a parent/primary caregiver and his/her child with DS? Further questions that guided the inquiry include: (a) what music therapy techniques 
are most appropriate for promoting parent-child interaction and (b) are there any common themes that emerge from the parent-child pairs?

\section{Methodology}

This paper is positioned in a constructionist epistemology. The researcher defined constructionism as the position that knowledge is created "through our engagement with the realities in our world" (Crotty, 1998, p. 8).For the current research, case study methodology offered the potential to capture a wealth of descriptive and detailed information about the participants' relationships that could be analysed qualitatively. Aldridge (2005) stated that, case study methodology offers a formal structure for stories, and stories provide rich and reliable information. Case examples, case histories, and case vignettes have been common ways to present music therapy practice (Smeijsters \& Aasgaard, 2005). Case studies provide a detailed examination of a particular event, a setting, a single subject or group, or a depository of documents (Bogdan \& Biklen, 2003)."The interest is in the process rather than outcomes, in context rather than a specific variable, and in discovery rather than confirmation" (Merriam, 1998, p. 19). This method allows for the evaluation, description and exploration of the phenomena in question.

This method allowed for flexibility in terms of data collection methods. Merriam (1998) noted that case study methodology does not claim any particular methods for data collection or analysis. Multiple sources of information were used and are reported in the current study - the researcher's field notes, , music utilised in the music therapy sessions, and weekly participation and observation in music therapy sessions. According to Patton (1990), multiple sources of data are used due to the fact that no single source of information can be trusted to provide a comprehensive perspective. Furthermore, by using a number of techniques, the researcher was able to utilise different data sources to validate her findings.

\section{Ethical Considerations}

Data collection for the current study involved human participants, therefore ethical approval was sought from the Arts, Humanities and Social Sciences Research Ethics. Key ethical implications associated with this study were: issues of privacy, right to withdraw, confidentiality, and the impact on participants of reporting sensitive personal data. Each of these issues was handled in accordance with standard procedures for the ethical conduct of research. At the beginning of the therapy process, written and signed informed consent was obtained from the CEO of the Creative Learning Centre as well as from the mothers before carrying out any research. This protected the participants, as well as the facility and ensured respect for the dignity of all persons involved (Wassenaar, 2006). The research does not provide the names of any person partaking in the research, ensuring their confidentiality and anonymity. Furthermore, to maintain the privacy and confidentiality of the participants, only the researcher, academic supervisors, and academic peers (during the peer review) had access to the data, which will be used solely for academic purposes. Informed consent ensured that no one was involved in this study without knowing about it and having a chance to refuse to take part.

\section{The Case}

Two mother-infant dyads (pairs) were selected for this research study in order to provide an in-depth understanding of the processes that occur in the relationship between a mother and her child with DS in music therapy. Purposive sampling was used in the current study as the researcher wanted to generate information about the effects of music therapy on parent-child interaction with a specific population (DS). The current research involved two children with DS and their mothers. Jason (pseudonym) was 3-years old and Sophie (pseudonym) was 9-months old.. Jason attended five music 
Table 1. Layout of the music therapy sessions

\begin{tabular}{|l|l|}
\hline \multicolumn{1}{|c|}{ Activity } & \multicolumn{1}{c|}{ Function } \\
\hline Greeting/Hello song & To encourage social awareness and responsiveness \\
\hline Well-known songs and nursery rhymes & To encourage participation \\
\hline Action and movement songs & $\begin{array}{l}\text { To provide the child with practice of fine and gross motor skills } \\
\text { as well as concept comprehension }\end{array}$ \\
\hline Instrumental play & $\begin{array}{l}\text { To provide further motor skills practice and also a focus on fol- } \\
\text { lowing directions }\end{array}$ \\
\hline Quiet, slow music and songs & To encourage closeness, attachment, and physical touch \\
\hline
\end{tabular}

therapy sessions while Sophie attended six music therapy sessions. The music therapy sessions ran from November to December of 2015.

Music therapy sessions were provided for the clients at the Creative Learning Centre. The centre was located in an enterprise estate with other companies with charitable status who have the mission of employment retention and generation, supporting neighbourhoods, and developing education. The building included office space, therapy rooms (music, art, and play), and meeting rooms. The therapy rooms were vibrantly coloured at the centre; blue for music, red for play, and yellow for art. There were many musical instruments in the room such as a keyboard, drum-kit, hand percussion instruments (shakers, tambourines, maracas, kalimbas, guiros, and chimes), and toys available as needed. These instruments and toys were accessible to the child as they were at floor-level and were easilyreached. In music therapy sessions, the researcher and participants sat on the floor with bean bags, cushions, and mats which encouraged participation and intervention. A sign was displayed outside the therapy room stating 'therapy in progress' which ensured that there were no external disruptions.

The music therapy interventions used by the researcher were applied from the Sing \& Grow (Abad \& Williams, 2007) program. Sessions were based on the main components of this program, including session structure, musical interventions, and parental strategies for promoting parent-child interaction. The program offered to the participants in this study provided mothers with opportunities to interact with their children in practical and spontaneous ways that helped to promote positive parent-child interaction. The music therapy sessions contained the following elements:

\section{Data Collection}

Marshall and Rossman (1989) defined observation as "the systematic description of events, behaviours, and artifacts in the social setting chosen for study" (p. 79). Observations provide a written snapshot of the subject or situation under study using the five senses (Erlandson, Harris, Skipper, \& Allen, 1993). Participant observation was used in the current research, connecting the researcher to participant experiences, discovering through immersion the whys and hows of music therapy and parent-child interaction.

Field notes provided the primary source of data in this study. Following each session, the researcher documented field notes about anything significant that occurred during the course of the session. The content of these field notes included basic observations and reactions to the participants and the process. Things that the researcher looked for included: the environment of the music therapy room, situation of the child in proximity to their mother, amount of interaction displayed, particular music and/or songs that enhanced parent-child interaction, and any other behaviours the researcher felt were important to the study and the understanding of the parent-child interaction in the music therapy session.

Unique to qualitative research methods is the identification of the researcher as a source of data. In the current study, the researcher is at the centre of the process and 
the instrument of data collection; in this way, experience, credibility, and qualifications of the researcher directly influence the study (Shenton, 2004).

\section{Results}

Analysis of the fieldwork notes revealed four large themes: namely (a) the mothers' involvement in music therapy, (b) interaction, (c) independence, and (d) characteristics of music therapy sessions. Themes were chosen not only because of prevalence across the participants, but also because they captured something important about the data in relation to the research question. The section belowdiscusses and analyses the themes as they unfolded during the course of music therapy intervention. To ensure anonymity, participants referred to in this text have been given pseudonyms, and reference numbers rather than a date provide a session number. Examples from the fieldwork notes are referenced with the child's name, mother, and session number and look like this: Sophie and Mother: 5 .

\section{To What Extent did the Mothers Participate in Music Therapy Sessions?}

The inclusion of the mothers in music therapy intervention with their children with DS led to several positive and consequential outcomes. Both mothers played an essential role in the formation of a secure base for the interaction with their children. Malekpour (2007), stated that attachment and interaction develop through reciprocal interactions between mother and child and 'positive' attachment and interaction occurs when the mother is not only nearby but also attentive and accessible. In the current study, the mothers' participation and involvement helped the children to feel safe and comfortable in the music therapy sessions. The children's need for external support was evident;

Sophie attended today's music therapy session with her mother. She was shy and preferred to stay in her mother's arms initially. Sophie turned away from music therapy student and faced inward toward mother (Sophie and Mother: 1).

When distressed, children often seek proximity to an attachment figure. In the current research, the children used proximity-seeking behaviours (e.g. crying, smiling) to keep their mothers nearby;

Jason attended today's session with his mother. He was quite tearful on arrival as he had bitten his tongue. Mother comforted Jason, telling him that he was ok and checking that he was feeling ok to continue with the music therapy session (Jason and Mother: 1).

Moreover there was clear dedication and engaged involvement from the mothers and a palpable desire by them to support and encourage their children;

... were very close during the instrument songs. Sophie copied her mother's actions during the shaker song where she lifted her arms and put her shaker in the air ... (Sophie and Mother: 3).

During the shaker song, Jason copied his mother's actions. She was delighted when he did such and praised him, "yes, that's right!" (Jason and Mother: 4).

The building blocks to attachment and interaction are formed by the capacity of a parent or caregiver to attune to his/her child's needs. The mothers in this research study showed wonderful moments of attunement with their children.

Nearing the end of the session, Sophie returned to her mother's arms and the two were very close and rocked/moved to the music together. Sophie was laughing and smiling, and mother appeared to be quite content (Sophie and Mother: 4).

The mothers' active involvement influenced Sophie and Jason's participation and involvement, and encouraged them to experiment with new ways of playing, learning, and interacting.

\section{Was there an Increase in Parent-child Interaction?}

Given the research question, it was inevitable that much of the focus in the data would be on parent-child interaction. This theme arose from the many patterns of reciprocal 
action that took place during the music therapy sessions. Music therapy provided a medium for increased connection and eye contact, as well as opportunities for interaction and play.

Throughout the music therapy sessions, the researcher found that the incidence of eye contact between the mothers and their children increased. The researcher describes a moment of connection between Sophie and her mother, where there was intimate interaction and synchrony;

During Twinkle, Twinkle, Little Star, Sophie faced her mother and watched her making diamond shapes, twinkling gestures and pointing upward to high in the sky. Sophie began to prolong vowel sounds and was giggling, looking at her mother every so often. The pair engaged very well, maintaining eye contact and were in very close proximity (Sophie and Mother: 6).

Sophie and Jason communicated with their mothers using vocalisations. This afforded the children and mothers a way to express and exchange information. Participants used face-to-face contact with alternating vocalisations as a primary form of interaction.

During the hello song, Sophie was vocal and used gestures to say hello to the student music therapist and mother. Mother appeared to be very satisfied with this and commented that, "she's really trying to say hello!" (Sophie and Mother: 2).

During the "Wheels on the Bus", Jason verbalized many times including "beep" and "bye" - bilabial sounds are present in his speech. He really enjoyed the action songs (Jason and Mother: 3).

Positive physical contact was observed in the music therapy sessions. Sophie and Jason frequently moved from very close physical proximity with their mothers to wider exploration of the music therapy space with frequent returns to the security of their safe base.

Sophie was confident and enjoyed exploring alone, looking at mother every so often (Sophie and Mother: 2).

Jason became sleepy and tended to move closer to his mother during this time - lying on her lap while she held and cuddled him (Jason and Mother: 4).

It would appear that eye contact, physical proximity, and playing construct the parent-child relationship (Barecellos, 2006). An increase in child-initiated interactions and verbal skills were observed during this therapy block. These results were consistent with those that Oldfield, Adams, and Bunce (2003) expounded where they emphasised that a variety of increases in a child's skills have been reported in the music therapy literature.

\section{How Did the Children Explore the Music Therapy Space?}

This theme reflects the shift from the dependence on the mother to autonomy. In the first music therapy session, Sophie arrived in her mother's arms, was quite introverted, and did not explore the room nor engage with the student music therapist. The following extract is taken from the final music therapy session, which is a significant example of change in Sophie's behaviour:

Straight away, Sophie picked up the beaters and began to play the metallophone. She was smiling and pointed one beater at the music therapy student, looking at her mother every so often. Sophie continued to hold and investigate the beaters throughout the action songs. She was vocal and laughed a lot (Sophie and Mother: 6).

The mothers in the current study provided a dual function; they were both a safe haven for the children to which to return for reassurance, as well as a secure based from which the children were able to explore;

Sophie alternated between exploring instruments and toys to returning to her mother's space and back to exploring again (Sophie and Mother: 2).

Jason was very interested in the guitar and strummed it from time to time. Other times he liked to explore the instruments and then put them away. He preferred to dance and 
move without instruments, and occasionally sat down or went over to his mother (Jason and Mother: 5).

Sophie and Jason both explored the music therapy space freely in the presence of their mothers. Over the weeks a pattern emerged of the children returning to their mothers for longer periods but also seeming to do more exploring. This suggests that they were feeling more secure and confident to explore the space. The children began to make their own choices, take initiative in music therapy activities, thereby influencing their development towards independence.

Jason was confident on arrival, leading mother and student music therapist toward the music therapy room (Jason and Mother: 3 ).

\section{What Were the Main Characteristics of the Music Therapy Sessions?}

Finally, the fourth theme relates to the musical and non-musical elements that influenced parent-child interactions. Music was used in many different ways in the sessions: vocal use, turn-taking through well-known songs, instrumental playing, and improvisation. Moreover, the researcher was seen as a feature of the music therapy sessions, as a facilitator using music to support and encourage interactions between the mothers and children. The researcher often removed herself slightly from the physical proximity of the mother-child pairs and allowed them space to explore the music therapy space together.

For many of these songs, Sophie was facing her mother therefore her back was turned to the music therapy student. I really felt like I was supporting their interaction as I was not in it, rather facilitating behind the curtains (Sophie and Mother: 3 ).

The researcher modelled positive, developmentally-appropriate interactions with children and presented opportunities for mothers to practice teaching, scaffolding, prompting, and providing reinforcement and praise to their child.

The format of the music therapy sessions allowed for repetition of activities, which provided the mothers with an opportunity to observe their children's developing skills. The non-verbal aspects of the music therapy sessions facilitated mutuality between the mother and child and provided playfulness and fun (Loveszy, 2006).

Jason's mother commented that she finds the sessions really enjoyable and that it's great to see Jason having so much fun (Jason and Mother: 4).

The well-known and action songs, such as "Wheels on the Bus", were presented as musical games in the music therapy sessions, where the mothers and children were required to interact with each other to achieve the desired outcome. These activities provided the student music therapist with an excellent opportunity for encouraging interactions between the mothers and their children, to highlight how the mothers can take delight in their children's interactions, and empower the mothers to interact with their children at home in a way that is healthy and conducive to the child's development. For example, "Where is Thumpkin" has actions that a parent can co-facilitate thus providing opportunity for touch and learning.

During Where is Thumpkin, mother demonstrated each finger to Sophie, and Sophie caught mother's finger in response. The two were in close proximity during the action songs (Sophie and Mother: 3).

Improvisatory techniques including improvised song and free improvisation were used in the music therapy sessions. Using free improvisation, the student music therapist provided space for the mother and child to explore musically and have fun. This was introduced during the course of the intervention rather than in the first few sessions, in order to build trust with the mothers and children so that they feel confident to explore musically without guidance. Edwards (2011) posited that building trust between mothers and children is critical in order for them to explore the music with confidence and without on-going guidance from the music therapy student. Observations clearly demonstrated the efficacy of this assertion, particularly since specific guidance was scaled back. 
Sophie began to explore during this activity, taking a particular interest in the metallophone. She played this using two beaters and she played a wide range from low notes to high notes. She demonstrated gross motor ability and concentration during her improvised playing. Vocalisations were also noted (Sophie and Mother: 3 ).

The music therapy student used improvised song to connect and engage the mothers and children using a song they knew but adapting it to suit a specific therapeutic situation. Toward the end of the music therapy sessions slow, quiet time songs were played. These included: "You Are My Sunshine", "Snowflake", "Four Hugs a Day", and "The Goodbye Song." The music therapy student substituted the children's names for 'sunshine' in "You are My Sunshine" which allowed for sensitive interactions between the mothers and children. It was during these slow, quiet songs of the session that the most affection and attachment was observed.

Sophie remained in her mother's arms for the rest of the session, cuddling into her mother. Mother kissed Sophie's forehead during these songs, and I could sense a great deal of attachment. During" You Are My Sunshine", I substituted Sophie's name for the sunshine spoken about in the song. Mother was quite attentive during this, cradling Sophie, singing to her and being very present in the moment (Sophie and Mother: 3).

Jason appeared to enjoy the feeling of the feathers as mother placed these on each facial feature in accordance with the "Snowflake" song. Jason really liked this activity and he smiled and laughed throughout. He was facing mother and the two were in close proximity. He remained in his mother's arms for the remainder of the session, where she cradled and hugged him for the ending songs (Jason and Mother: 3 ).

"By providing a musical container, or skin, in which both the parent and infant can be held, music therapy can offer the dyad a chance to safely encounter and explore one another anew" (Edwards, 2011). Music techniques facilitated the journey from the mother's involvement, to interaction, leading to the child's independence.

\section{Discussion}

The overall aim of this research was to explore the effects of music therapy on parentchild interaction, specifically focusing on children with DS.The findings of this study support those of earlier studies that indicate music can facilitate parent-child interactions and enhance parent-child attachment (Nicholson, Berthelsen, Abad, Williams, \& Bradley, 2008). The music therapy techniques encouraged parents to be more responsive and less directive during parent-child interactions. Throughout this music therapy block, the mothers learned to adjust and adapt their interaction styles according to their children's behavioural characteristics and needs, while the children learned to engage and to share musical activities with their parents.

With regards to early intervention for children with DS, it is important to consider Hanson's (2003) follow-up investigation with children with DS and their families 25 years after participation in an early intervention programme. Findings from this study indicated that all parents involved listed early intervention as one of the most important supports they received. For parents, it was a "lifeline" in which they received hope and support. For the children involved, developmental milestones were achieved during this time to include sitting up, walking, and toilet training. Given the well established associations between parent-child interactions and positive child development, these findings are important to families and music therapists. They are a promising indication that early interventions can be effective in contributing to the development of positive life trajectories for young children.The current research is significant for music therapists working in the area of disability, particularly within an Irish context as Ireland has the highest prevalence rate of DS in Europe (Down's syndrome Medical Interest Group, 2001).

\section{Limitations and Recommendations of the Study}

The study has limitations, and further investigation may be helpful in gaining deeper insights into further opportunities that music therapy might afford a parent/primary 
caregiver and his/her child with DS, as well as informing the inclusion of the parent/ primary caregiver in music therapy sessions. The research material only explores the researcher's fieldwork notes. Due to the complexities of parent-child relationships, it may be necessary to gain deeper insights by including an interview with the parent/ primary caregiver in future studies. Furthermore, the researcher suggests recording music therapy sessions using video and audio applications for a detailed analysis. Because of the parent characteristics and the sample size in this case study, findings need to be interpreted with caution and cannot be generalised to the whole population of families with young children who have DS.

\section{References}

Abad, V., \& Edwards, J. (2004). Strengthening families: A role for music therapy in contributing to family centred care. Australian Journal of Music Therapy, 15, 3-17.

Abad, V., \& Williams, K. (2007). Early intervention music therapy: Reporting on a 3-year project to address needs with at-risk families. Music Therapy Perspectives, 25, 52-58, http://dx.doi.org/10.1093/mtp/25.1.52.

Ainsworth, M. D. S., Bell, S. M., \& Stayton, D. J. (1974). Infant-mother attachment and social development: "Socialisation" as a product of reciprocal responsiveness to signals. In M. J. M. Richards (Ed.), The integration of a child into a social world (pp. 9-135). London: Cambridge University Press.

Ainsworth, M. D. S., Blehar, M. C., Waters, E., \& Wall, S. (1978). Patterns of attachment: A psychological study of the strange situation. Hillsdale, NJ: Erlbaum.

Aldridge, D. (2005). Case study designs in music therapy. Philadelphia: Jessica Kingsley Publishers.

Allgood, N. (2005). Parents' perceptions of family-based group music therapy for children with autism spectrum disorders. Music Therapy Perspectives, 23, 92-99, http://dx.doi.org/ $10.1093 / \mathrm{mtp} / 23.2 .92$.

Barcellos, L. (2006). Familiarity, comfortableness and predictability of song as "holding environment" for mothers of premature babies. Voices: A World Forum For Music Therapy, 6(1), http://dx.doi.org/10.15845/voices.v6i1.243.

Bogdan, R. C., \& Biklen, S. K. (2003). Qualitative research for education: An introduction to theories and methods (4th ed.). New York, NY: Pearson Education group.

Bowlby, J. (1982). Attachment and loss. York, NY: Basic Books.

Cicchetti, D., \& Beeghly, M. (Eds.). (1990). Children with Down syndrome: A developmental perspective. New York, NY: Cambridge University Press. http://dx.doi.org/10.1017/ CBO9780511581786.

Crotty, M. (1989). The foundations of social research. England: Sage.

Cunningham, J. (2011). Music therapy to promote attachment between mother and baby in marginalized communities. In J. Edwards (Ed.), Music therapy and parent-infant bonding (pp. 115-126). Oxford, England: Oxford University Press. http://dx.doi.org/10.1093/acprof:oso/ 9780199580514.003.0009.

Daudt, A. (2002). Children with Down syndrome and music: A parental description of their experience in music. Unpublished masters' thesis, MCP Hahnemann University, Philadelphia.

de l'Etoile, S. K. (2006). Infant behavioral responses to infant-directed singing and other maternal interactions. Infant Behavior and Development, 29(3), 456-470, http://dx.doi.org/ 10.1016/j.infbeh.2006.03.002.

Down Syndrome Ireland (2013). Student Information Booklet. Retrieved from http://downsyndrome.ie/wp-content/uploads/2013/12/DSI_StudentPack_Home.pdf

Down's syndrome Medical Interest Group (DSMIG) UK and Ireland. (2001). Medical management of children and adolescents with Down syndrome in Ireland. Retrieved from http://www.downsyndromelimerick.ie/index.php/docs? download = 3:medical-guidelinesfor-children-with-down-syndrome. 
Edwards, J. (2011). The use of music therapy to promote attachment between parents and infants. The Arts in Psychotherapy, 38, 190-195, http://dx.doi.org/10.1016/ j.aip.2011.05.002.

Erikson, E. (1950). Childhood and society. York, NY: Norton.

Erlandson, D. A., Harris, E. L., Skipper, B. L., \& Allen, S. D. (1993). Doing naturalistic inquiry: A guide to methods. Newbury Park, CA: Sage.

Frid, C., Drott, P., Lundell, B., Rasmussen, F., \& Annerén, G. (1999). Mortality in Down's syndrome in relation to congenital malformations. Journal of Intellectual Disability Research, 43(3), 234-241, http://dx.doi.org/10.1046/j.1365-2788.1999.00198.x.

Gilboa, A., \& Roginsky, E. (2010). Examining the dyadic music therapy treatment (DUET): The case of a CP child and his mother. Nordic Journal of Music Therapy, 19, 103-132, http://dx.doi.org/10.1080/08098131.2010.500742.

Goldberg, S. (2000). Attachment and development. London, England: Arnold.

Guba, E. G., \& Lincoln, Y. S. (1994). Competing paradigms in qualitative research. In N. K. Denzin \& Y. S. Lincoln (Eds.), Handbook of qualitative research (pp. 105-117). Thousand Oaks, CA: Sage.

Hanson, M. J. (2003). Twenty-five years after early intervention. Infants \& Young Children, 16(4), 354-365, http://dx.doi.org/10.1097/00001163-200310000-00008.

Hoey, J., \& Murphy, J. (2006). Medical management of children \& adolescents with Down syndrome in Ireland. Dublin, Ireland: Trinity College.

Loveszy, R. R. (2006). Musical journeys: Music therapy with Latin American mother-infant dyads in a substance abuse rehabilitation program. Doctoral dissertation, New York University, 2006. Dissertation Abstracts International, 66(12).

Malekpour, M. (2007). Effects of attachment on early and later development. The British Journal of Developmental Disabilities, 53(2), 81-95, http://dx.doi.org/10.1179/ 096979507799103360.

Marshall, C., \& Rossman, G. B. (1989). Designing qualitative research. Newbury Park, CA: Sage.

Merriam, S. B. (1998). Qualitative research and case study applications in education. San Francisco, CA: Jossey-Bass.

Nicholson, J. M., Berthelsen, D., Abad, V., Williams, K., \& Bradley, J. (2008). Impact of music therapy to promote positive parenting and child development. Journal of Health Psychology, 13(2), 226-238, http://dx.doi.org/10.1177/1359105307086705.

Oldfield, A., Adams, M., \& Bunce, L. (2003). An investigation into short-term music therapy with mothers and young children. British Journal of Music Therapy, 17(1), 26-45, http://dx.doi.org/10.1177/135945750301700105.

Patton, M. Q. (1990). Qualitative evaluation and research methods. London, England: SAGE publications.

Pienaar, D. (2012). Music therapy for children with Down syndrome: Perceptions of caregivers in a special school setting. Kairaranga, 13(1), 36-43.

Saxton, M. (2008). What's in a name? Coming to terms with the child's linguistic environment. Journal of Child Language, 35(3), http://dx.doi.org/10.1017/S0305000907008562.

Selikowitz, M. (1990). Down syndrome: The facts. Oxford: Oxford University Press.

Selikowitz, M. (2008). Down syndrome - The facts (3rd ed.). Oxford, England: Oxford University Press.

Serafica, F. C., \& Cicchetti, D. (1976). Down's syndrome children in the strange situation: Attachment and exploratory behaviours. Merrill-Palmer Quarterly, 21, 137-150.

Shenton, A. K. (2004). Stratefies for ensuring trustworthiness in qualitative research projects. Education for Information, 22, 63-75.

Smeijsters, H., \& Aasgaard, T. (2005). Qualitative case study research. In B. L. Wheeler (Ed.), Music therapy research (2nd ed., pp. 240-257). Gilsum, NH: Barcelona.

Stern, D. N. (1985). The inter personal world of the infant. York, NY: Basic Books. 
Turner, S., \& Alborz, A. (2003). Academic attainments of children with Down's syndrome: A longitudinal study. British Journal of Educational Psychology, 73(4), 563-583, http://dx.doi.org/10.1348/000709903322591244.

Trehub, S. E. (2009). Music lessons from infants. In S. Hallam, I. Cross, \& M. Thaut (Eds.), Oxford handbook of music psychology (pp. 229-234). Oxford, England: Oxford University Press.

Trevarthen, C. (2004). How infants learn how to mean. In M. Tokoro \& L. Steels (Eds.), A learning zone of one's own (pp. 37-69). The Netherlands: IOS Press.

Vaughn, B. E., Goldberg, S., Atkinson, L., Marcovitch, S., MacGregor, D., \& Seifer, R. (1994). Quality of toddler-mother attachment in children with Downsyndrome: Limits to interpretation of strange situation behavior. Child Development, 65(1), 95, http://dx.doi.org/10.2307/1131368.

Wassenaar, D. R. (2006). Ethical issues in social science research. In M. Terre Blanche, M. Durrheim, \& D. Painter (Eds.), Research in practice (2nd ed., pp. 60-79). South Africa: Juta.

Waters, E., \& Cummings, E. M. (2000). A secure base from which to explore close relationships. Child Development, 71, 164-172, http://dx.doi.org/10.1111/ 1467-8624.00130. 